\title{
Magnesium causes nitric oxide independent coronary artery vasodilation in humans
}

\author{
H Teragawa, M Kato, T Yamagata, H Matsuura, G Kajiyama
}

\begin{abstract}
Objective-To determine how magnesium affects human coronary arteries and whether endothelium derived nitric oxide (EDNO) is involved in the coronary arterial response to magnesium.

Design-Quantitative coronary angiography and Doppler flow velocity measurements were used to determine the effects of the nitric oxide synthase inhibitor $N^{\mathrm{G}}$-monomethyl-L-arginine (L-NMMA) on magnesium induced dilation of the epicardial and resistance coronary arteries.

Setting-Hiroshima University Hospital a tertiary cardiology centre. Patients-17 patients with angiographically normal coronary arteries.

Interventions-Magnesium sulfate $\left(\mathrm{MgSO}_{4}\right)(0.02 \mathrm{mmol} / \mathrm{min}$ and $0.2 \mathrm{mmol} / \mathrm{min})$ was infused for two minutes into the left coronary ostium before and after intracoronary infusion of L-NMMA.

Main outcome measures-Diameter of the proximal and distal segments of the epicardial coronary arteries and coronary blood flow.

Results-At a dose of $0.02 \mathrm{mmol} / \mathrm{min}, \mathrm{MgSO}_{4}$ did not affect the coronary arteries. At a dose of $0.2 \mathrm{mmol} / \mathrm{min}, \mathrm{MgSO}_{4}$ caused coronary artery dilation (mean (SEM) proximal diameter 3.00 (0.09) to $3.11(0.09) \mathrm{mm}$; distal $1.64(0.06)$ to $1.77(0.07) \mathrm{mm}$ ) and increased coronary blood flow (79.3 (7.5) to $101.4(9.9) \mathrm{ml} / \mathrm{min}, \mathrm{p}<0.001 v$ baseline for all). $\mathrm{MgSO}_{4}$ increased the changes in these parameters after the infusion of L-NMMA ( $p<0.001 v$ baseline).

Conclusions-Magnesium dilates both the epicardial and resistance coronary arteries in humans. Furthermore, the coronary arterial response to magnesium is dose dependent and independent of EDNO.

(Heart 2001;86:212-216)
\end{abstract}

Keywords: coronary artery; coronary blood flow; magnesium sulfate; nitric oxide

Much interest has been focused on the relation between magnesium and cardiovascular disease. ${ }^{1-3}$ Furthermore, the benefits of magnesium administration have been shown in a variety of cardiovascular diseases. ${ }^{4-7}$ In the setting of coronary artery disease, several studies have shown the efficacy of magnesium infusion in patients with acute myocardial infarction, ${ }^{4}$ vasospastic angina, ${ }^{5}$ and unstable angina. ${ }^{8}$ While several mechanisms are probably responsible for the favourable effects of magnesium, the coronary vasodilatory effect seems to be the primary mechanism responsible for the beneficial effects of magnesium. ${ }^{9-11}$ However, only a few studies have investigated human coronary responses to magnesium infusion in vivo. ${ }^{12} 13$

One potential mechanism responsible for magnesium induced coronary dilation involves activation of the endothelium derived nitric oxide (EDNO) pathway. ${ }^{14-17}$ However, it is unclear whether EDNO is involved in the human coronary responses to magnesium. Therefore, in the present study we investigated the coronary vascular responses to intracoronary infusion of magnesium. In addition, we determined whether EDNO contributes to the coronary vascular response to magnesium by using $N^{\mathrm{G}}$-monomethyl-L-arginine (L-NMMA), a nitric oxide synthase inhibitor.

\section{Methods}

STUDY POPULATION

We studied 17 Japanese patients (mean age 62 years, range 44-69 years; seven men, 10 women) undergoing coronary angiography for the evaluation of chest pain. Chest pain was atypical for effort angina in all of the patients. All patients had angiographically normal epicardial coronary arteries, normal left ventricular function (contrast ventriculographic ejection fraction $\geqslant 50 \%$ ) and a normal coronary flow reserve. Patients with angiographically documented coronary spasm ( $>50 \%$ luminal narrowing) after intracoronary injection of acetylcholine were excluded from the study.

No patients had a history of prior myocardial infarction, heart failure, or other serious diseases. Written informed consent was obtained from all patients before the study. The protocol was approved by the human investigation ethics committee of Hiroshima University.

\section{STUDY DESIGN}

The study design has been previously described in detail. ${ }^{18}$ In brief, all drugs including antianginal agents were discontinued 48 hours before catheterisation, except for the unrestricted use of sublingual glyceryl trinitrate, which was withheld 1 hour before catheterisation. A 6 French guide catheter was introduced into the left main coronary artery. A 0.0014 inch Doppler flow guide wire (FloWire, Cardiometrics, Mountain View, USA) was advanced through the guide catheter into the proximal segment of the left anterior descending coronary artery. The wire tip was carefully positioned in a straight segment of the vessel to obtain an adequate flow velocity signal. 
$<$ th;2> Table $1 \quad$ Systemic haemodynamic and coronary diameter and blood flow variables

\begin{tabular}{|c|c|c|c|c|c|}
\hline & \multirow[b]{2}{*}{$\begin{array}{l}\text { HR } \\
\text { (beats/min) }\end{array}$} & \multirow[b]{2}{*}{$\begin{array}{l}M A P(m m \\
H g)\end{array}$} & \multicolumn{2}{|c|}{ Coronary diameter $(\mathrm{mm})$} & \multirow[b]{2}{*}{$\begin{array}{l}\text { Coronary blood flow } \\
\text { (ml/min) }\end{array}$} \\
\hline & & & Proximal segments & Distal segments & \\
\hline Baseline before L-NMMA & $68(2)$ & $108(4)$ & $3.00(0.09)$ & $1.64(0.06)$ & $79.3(7.5)$ \\
\hline Low $\mathrm{MgSO}_{4}$ & $69(2)$ & $105(4)$ & $3.03(0.09)$ & $1.67(0.06)$ & $82.8(7.3)$ \\
\hline High $\mathrm{MgSO}_{4}$ & $68(3)$ & $105(4)$ & $3.11(0.09)^{\star} \dagger$ & $1.77(0.07)^{\star} \dagger$ & $101.4(9.9)^{\star} \dagger$ \\
\hline Baseline after L-NMMA & $67(2)$ & $108(4)$ & $2.89(0.09)^{\star \star}$ & $1.58(0.06)^{\star \star}$ & $68.3(6.1)^{\star \star}$ \\
\hline Low $\mathrm{MgSO}_{4}$ & $68(2)$ & $106(4)$ & $2.93(0.08)$ & $1.62(0.06)$ & $71.7(7.4)$ \\
\hline High $\mathrm{MgSO}_{4}$ & $67(3)$ & $106(3)$ & $3.01(0.09)^{\star}+$ & $1.67(0.06)^{\star} \ddagger$ & $86.2(8.3)^{\star} \dagger$ \\
\hline Glyceryl trinitrate & $75(3) \sqrt{9}$ & $98(4)$ đ́ & $3.26(0.09) \Omega^{\circ}$ & $1.95(0.06) \S$ & $98.4(12.0)+\dagger$ \\
\hline
\end{tabular}

Values are mean (SEM)

Low $\mathrm{MgSO}_{4}$ was at a dose of $0.02 \mathrm{mmol} / \mathrm{min}$; high $\mathrm{MgSO}_{4}$ was at a dose of $0.2 \mathrm{mmol} / \mathrm{min}$.

$\mathrm{HR}$, heart rate; L-NMMA, $\mathrm{N}^{\mathrm{G}}$-monomethy-L-arginine; MAP, mean arterial pressure.

${ }^{\star} \mathrm{p}<0.001 v$ baseline; $\nmid \mathrm{p}<0.01 v$ low $\mathrm{MgSO}_{4} ; \neq \mathrm{p}<0.05 v$ low $\mathrm{MgSO}_{4} ;{ }^{\star \star} \mathrm{p}<0.05 v$ baseline before L-NMMA; †tp $<0.05 v$ others except high $\mathrm{MgSO}_{4} ; \mathrm{Sp}<0.001 v$ others; $\lceil\mathrm{p}<0.01 v$ others.

STUDY PROTOCOL

After baseline control conditions were established, magnesium sulfate $\left(\mathrm{MgSO}_{4}\right)$ was infused at rates of 0.02 and $0.2 \mathrm{mmol} / \mathrm{min}$ for 2 minutes. These doses were determined based on preliminary studies performed in six other patients who had undergone cardiac catheterisation. On the basis of these preliminary studies, intracoronary infusion of $\mathrm{MgSO}_{4}$ at the doses used in the present study had no effects on either systemic haemodynamic variables or systemic serum electrolyte concentrations and did not cause conduction disturbance. In contrast, these doses caused significant increases in the serum ionised magnesium concentration in the coronary sinus (mean baseline concentration (SEM): $0.50(0.02) \mathrm{mmol} / \mathrm{l} ; 0.02 \mathrm{mmol} /$ min: $0.65(0.04) \mathrm{mmol} / \mathrm{l}, \mathrm{p}<0.01 v$ baseline; $0.2 \mathrm{mmol} / \mathrm{min}: \quad 1.65 \quad(0.15) \mathrm{mmol} / \mathrm{min}$, $\mathrm{p}<0.001 v$ baseline). After 5 minutes, L-NMMA was infused into the left coronary artery at a rate of $40 \mu \mathrm{mol} / \mathrm{min}$ for five minutes. After control conditions had been reestablished, $\mathrm{MgSO}_{4}(0.02$ and $0.2 \mathrm{mmol} / \mathrm{min})$ was again infused serially. Finally, an intracoronary infusion of glyceryl trinitrate was given at a rate of $200 \mu \mathrm{g} / \mathrm{min}$ for one minute. All drugs were infused directly into the left coronary ostium through a catheter using an infusion pump (TE-311, Terumo, Tokyo, Japan) set at a rate of $1 \mathrm{ml} / \mathrm{min}$.

Coronary angiography was performed under control conditions and at the end of each drug administration. The coronary blood flow velocity was monitored continuously by a $12 \mathrm{MHz}$ pulsed Doppler velocimeter (FloMap, Cardiometrics). Arterial pressure, heart rate, and ECG were monitored continuously and recorded by a multichannel recorder (Nihonkoden Polygraph System, Nihonkoden, Tokyo, Japan). We waited at least five minutes after each drug infusion to obtain stable values for blood flow velocity and coronary diameter.

QUANTITATIVE CORONARY ANGIOGRAPHY

The trunk of the left anterior descending and left circumflex coronary artery were divided into the proximal and distal segments of equal lengths. In each patient, the luminal diameters of the proximal and distal segments of the left anterior descending and left circumflex coronary arteries were measured to determine the effects of various drugs on epicardial coronary diameters. The luminal diameters were measured without knowledge of the clinical characteristics of the patients. An end diastolic frame was selected and analysed by a computer assisted coronary angiographic analysis system (CAAS II/QUANTCOR, Siemens AG, Berlin and Munich, Germany). The average values of triplicate measurements of luminal diameter were used for analysis.

ESTIMATION OF CORONARY BLOOD FLOW

Coronary blood flow was calculated as the product of coronary blood flow velocity and vessel diameter using the following formula: $\pi \times$ average peak velocity $\times 0.125 \times$ diameter $^{2}$. For calculating coronary blood flow, the internal diameter of the vessel at the location of the flow measurements $(2-3 \mathrm{~mm}$ distal to the wire tip) was measured using the method described above.

BIOCHEMICAL PARAMETERS

Venous blood was drawn from a femoral sheath before the first and second administration of magnesium to measure serum ionised magnesium and calcium concentrations using a selective ion electrode (NOVA 8; NOVA Biomedical, Waltham, USA). All measurements were performed in duplicate.

\section{DRUG PREPARATIONS}

$\mathrm{MgSO}_{4}$ (Toa Pharmaceutical Co, Tokyo, Japan) was dissolved in an isotonic glucose solution. L-NMMA (Sigma) and glyceryl trinitrate (Nihonkayaku, Tokyo, Japan) were dissolved immediately before use in physiological saline. L-NMMA was sterilised in the department of pharmacy of Hiroshima University Hospital.

\section{STATISTICAL ANALYSIS}

All data are expressed as the mean (SEM). Serial changes in haemodynamic variables, epicardial coronary diameter, and coronary blood flow in response to $\mathrm{MgSO}_{4}$ were compared by one way analysis of variance (ANOVA). Serial changes in the epicardial coronary diameter and coronary blood flow before and after the administration of L-NMMA were compared by two way ANOVA. Paired data were compared by Wilcoxon signed ranks test. A probability value of $p<0.05$ was considered significant. 


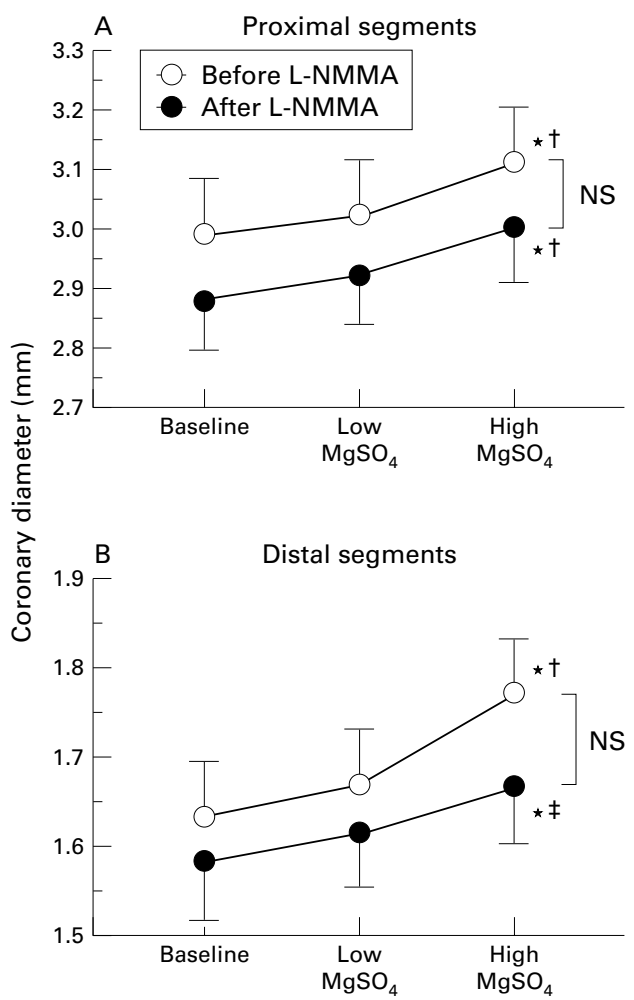

Figure 1 Changes in the diameter of the $(A)$ proximal and $(B)$ distal segments of epicardial coronary arteries in response to intracoronary infusion of $\mathrm{MgSO}_{4}$ before and after infusion of $\mathrm{N}^{G}$-monomethyl-L-arginine (L-NMMA). Low $\mathrm{MgSO}_{4}$ was at a dose of $0.02 \mathrm{mmol} / \mathrm{min}$; high $\mathrm{MgSO}_{4}$ was at a dose of $0.2 \mathrm{mmol} / \mathrm{min}$. Vertical bars represent SEM. ${ }^{\star} p<0.001$ v baseline; $t p<0.01$ v low $\mathrm{MgSO}_{4}$; $\neq p<0.05$ v low $\mathrm{MgSO}_{4}$.

\section{Results}

CLINICAL CHARACTERISTICS

Three patients were current smokers $(>10$ cigarettes/day), but were instructed not to smoke for at least 48 hours before the study. Five patients had hypertension but no echocardiographic evidence of left ventricular hypertrophy. Hypercholesterolaemia (total serum cholesterol concentration $>240 \mathrm{mg} / \mathrm{dl}$ $(>6.2 \mathrm{mmol} / \mathrm{l})$ ) was present in five patients, but their total serum cholesterol concentrations were not more than $270 \mathrm{mg} / \mathrm{dl}(7 \mathrm{mmol} / \mathrm{l})$ while not receiving antihypercholesterolaemia drug treatment. One patient had diet controlled diabetes mellitus.

HAEMODYNAMIC VARIABLES

There were no significant changes in either heart rate or mean arterial pressure at baseline or during the infusion of various drugs, except during the infusion of glyceryl trinitrate. With the infusion of glyceryl trinitrate, the heart rate increased and the mean arterial pressure decreased (table 1).

\section{ELECTROLYTE VARIABLES}

The serum ionised magnesium and calcium concentrations at baseline did not change (magnesium: $0.51 \quad(0.02) \mathrm{mmol} / 1$ and 0.52 (0.02) $\mathrm{mmol} / \mathrm{l}$ before the first and second infusion of $\mathrm{MgSO}_{4}$, respectively, $\mathrm{p}=\mathrm{NS}$; calcium: $1.14(0.01) \mathrm{mmol} / \mathrm{l}$ and $1.13(0.01) \mathrm{mmol} / \mathrm{l}$ before the first and second infusion of $\mathrm{MgSO}_{4}$, respectively, $\mathrm{p}=\mathrm{NS}$ ).

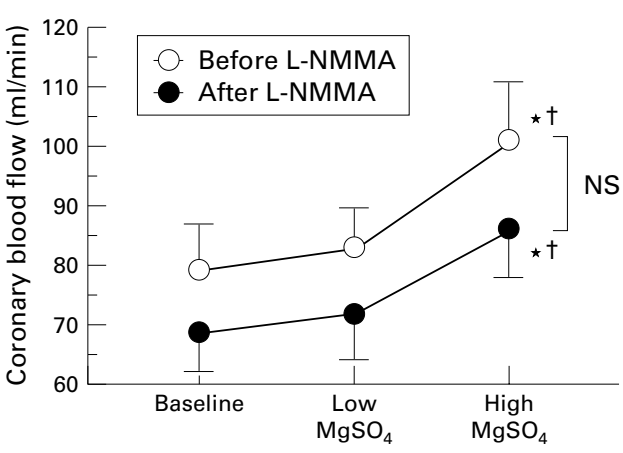

Figure 2 Changes in coronary blood flow in response to intracoronary infusion of $\mathrm{MgSO}_{4}$ before and after L-NMMA infusion. Vertical bars represent SEM. ${ }^{*} p<0.001 v$ baseline and $t p<0.01 v$ low $\mathrm{MgSO}_{4}$.

CORONARY RESPONSE TO L-NMMA AND GLYCERYL TRINITRATE

After intracoronary infusion of L-NMMA, the coronary diameter at baseline decreased from $3.00(0.09) \mathrm{mm}$ to $2.89(0.09) \mathrm{mm}(\mathrm{p}<0.05)$ in the proximal segment and from 1.64 $(0.06) \mathrm{mm}$ to $1.58(0.06) \mathrm{mm}(\mathrm{p}<0.05)$ in the distal segment (table 1). Furthermore, after the infusion of L-NMMA, coronary blood flow at baseline decreased from $79.3(7.5) \mathrm{ml} / \mathrm{min}$ to $68.3(6.1) \mathrm{ml} / \mathrm{min}$ ( $\mathrm{p}<0.05$, table 1$)$. After the intracoronary infusion of glyceryl trinitrate, the coronary diameter at baseline increased from $3.00(0.09) \mathrm{mm}$ to $3.26(0.09) \mathrm{mm}$ $(\mathrm{p}<0.001)$ in the proximal segment and from

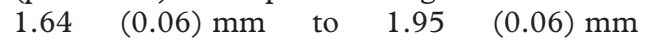
$(\mathrm{p}<0.001)$ in the distal segment (table 1$)$.

CORONARY RESPONSE TO MAGNESIUM INFUSION At a low dose $(0.02 \mathrm{mmol} / \mathrm{l})$, the intracoronary infusion of $\mathrm{MgSO}_{4}$ caused small increases in the coronary diameter (proximal segment: 3.03 (0.09) $\mathrm{mm}$; distal segment: $1.67(0.06) \mathrm{mm}$; table 1 and fig 1) and coronary blood flow (82.8 (7.3) $\mathrm{ml} / \mathrm{min}$; table 1 and fig 2), although these values did not reach significance. At a high dose $(0.2 \mathrm{mmol} / \mathrm{l}), \mathrm{MgSO}_{4}$ caused significant dilation of the proximal segment (3.11 $(0.09) \mathrm{mm})$ and distal segment (1.77 $(0.07) \mathrm{mm}$, both $\mathrm{p}<0.001 v$ baseline and $\mathrm{p}<0.01 v$ low dose; table 1 and fig 1). This was associated with increased coronary blood flow $(101.4(9.9) \mathrm{ml} / \mathrm{min}, \mathrm{p}<0.001 v$ baseline and $\mathrm{p}<0.01 v$ low dose; table 1 and fig 2 ).

EFFECT OF L-NMMA ON MAGNESIUM INDUCED CORONARY RESPONSE

After intracoronary infusion of L-NMMA, low dose $\mathrm{MgSO}_{4}$ caused small increases in the coronary diameter (proximal segment: 2.93 (0.08) $\mathrm{mm}$; distal segment: $1.62(0.06) \mathrm{mm}$; table 1 and fig 1) and coronary blood flow (71.7 (7.4) $\mathrm{ml} / \mathrm{min}$; table 1 and fig 2), although these values were not different. After the infusion of L-NMMA, high dose $\mathrm{MgSO}_{4}$ caused significant dilation of the proximal segment (3.01 (0.09) mm, p < $0.001 v$ baseline and $\mathrm{p}<0.01 v$ low dose) and distal segment (1.67 (0.06) mm, p $<0.001 v$ baseline and $\mathrm{p}<0.05$ $v$ low dose; table 1 and fig 1). After infusion of L-NMMA, high dose $\mathrm{MgSO}_{4}$ increased coronary blood flow $(86.2(8.3) \mathrm{ml} / \mathrm{min}, \mathrm{p}<0.001 v$ 
baseline and $\mathrm{p}<0.01 v$ low dose; table 1 and fig 2). These changes in coronary diameter and blood flow in response to the intracoronary infusion of $\mathrm{MgSO}_{4}$ were not altered by the infusion of L-NMMA (figs 1 and 2).

\section{Discussion}

The present study shows that the intracoronary infusion of magnesium causes dilation of human coronary arteries, including the epicardial and resistance coronary arteries, in vivo in a dose dependent manner. Furthermore, the present study shows that EDNO does not mediate magnesium induced coronary dilation. To our knowledge, this is the first description of the relation between EDNO and magnesium induced human coronary dilation.

COMPARISON WITH PREVIOUS REPORTS

There have been very few studies of the changes in human blood flow in response to magnesium infusion in vivo. ${ }^{12} 1319$ Fujita and colleagues $^{19}$ showed that intra-arterial infusion of $\mathrm{MgSO}_{4}$ decreases forearm vascular resistance. Vigorito and associates found that coronary blood flow increases in normal, ${ }^{12}$ but not ischaemic, human coronary arteries ${ }^{13}$ after intravenous infusion of $\mathrm{MgSO}_{4}$. However, in these reports, the response to magnesium was determined in peripheral or coronary resistance vessels. Before the present study, there were no reports concerning changes in human conductance and resistance coronary arteries in response to magnesium infusion in vivo.

EFFECT OF MAGNESIUM ON CORONARY ARTERIES The present study shows that intracoronary infusion of high dose $\mathrm{MgSO}_{4}$ causes dilation of coronary arteries and increases in coronary blood flow. In contrast, the changes in these parameters did not reach significance with the intracoronary infusion of low doses of $\mathrm{MgSO}_{4}$. These findings suggest that the coronary response to magnesium is dose dependent. The dose dependent blood flow response to magnesium infusion is in keeping with previous reports of forearm blood flow. ${ }^{19}$

In the present study, both the resistance and epicardial coronary arteries dilated in response to a high dose of $\mathrm{MgSO}_{4}$. Furthermore, this response was not inhibited by L-NMMA. Because our previous study ${ }^{20}$ showed that L-NMMA does not inhibit adenosine induced, flow mediated dilation of human epicardial coronary arteries, we cannot exclude the possibility that dilation of the epicardial coronary arteries by magnesium infusion is caused by flow mediated dilation. However, it remains to be determined how increases in coronary blood flow can cause flow mediated dilation of the epicardial coronary arteries. Because the increase in coronary blood flow induced by magnesium infusion is less than that induced by adenosine infusion, ${ }^{21}$ the increase in coronary blood flow induced by magnesium may be insufficient to cause flow mediated dilation of epicardial coronary arteries. Therefore, we believe that the dilation of epicardial coronary arteries observed in the present study may be caused by a direct action of magnesium on coronary arteries.

MECHANISM OF MAGNESIUM INDUCED CORONARY DILATION

Several mechanisms responsible for magnesium induced coronary dilation have been hypothesised. Magnesium is a physiological calcium blocker, ${ }^{22}$ and previous studies ${ }^{23-25}$ have established that extracellular magnesium inhibits calcium entry into vascular smooth muscle cells. Fujita and colleagues ${ }^{19}$ showed that co-infusion of magnesium and calcium blunted the vasodilatory actions observed by magnesium infusion alone, suggesting that magnesium induced dilation is caused by the antagonistic actions between magnesium and calcium. It is also possible that magnesium modulates adenosine 3',5'-monophosphate formation through adenylate cyclase, which is activated by magnesium. ${ }^{23} 26$ Therefore, magnesium infusion may cause an increase in adenosine 3',5'-monophosphate production within coronary smooth muscle cells, leading to the dilation of coronary arteries.

Several studies have shown that prostacyclin, which is the vasodilating substance produced by the vascular endothelium, is involved in the vasodilatory action of magnesium. ${ }^{27-29} \mathrm{Al}-$ though some studies have had opposite findings, ${ }^{30}{ }^{31} \mathrm{Ravn}^{32}$ reported that there are large interindividual and intraindividual variations in prostacyclin release. Therefore, although many observations are needed to quantify the amount of prostacyclin released by magnesium infusion, it is likely that endothelial release of prostacyclin contributes to the vasodilatory effect of magnesium.

DOES EDNO CONTRIBUTE TO MAGNESIUM INDUCED HUMAN CORONARY DILATION IN VIVO?

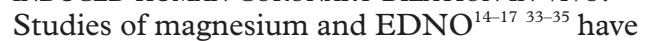
presented contradictory hypotheses concerning the relation between magnesium induced vascular dilation and EDNO. One hypothesis is that EDNO is involved in magnesium induced vascular dilation. ${ }^{14-17}$ The studies that support this hypothesis were all performed in animals. However, there have been no reports concerning magnesium induced coronary response and EDNO in humans. In our study, the dilation of human epicardial coronary arteries and the increase in coronary blood flow induced by intracoronary infusion of magnesium were not affected by L-NMMA. On the basis of these findings, we conclude that EDNO is not involved in magnesium induced human coronary dilation. The differences in species, types of vessels, and concentrations of magnesium used between previous studies and this study may account for the differing results. The second hypothesis is that magnesium inhibits the release of EDNO. ${ }^{33-35}$ This hypothesis suggests that infusion of magnesium does not cause EDNO mediated dilation. Our results support this second hypothesis.

STUDY LIMITATIONS

There are several limitations to the present study. First, the dose of L-NMMA may have 
been insufficient to inhibit EDNO production completely. The baseline coronary diameter and coronary blood flow decreased after infusion of L-NMMA, indicating that the dose of L-NMMA was sufficient to inhibit basal EDNO production. However, the dose may have been insufficient to inhibit magnesium induced EDNO production. Quyyumi and colleagues $^{36}$ infused L-NMMA at a dose of $64 \mu \mathrm{mol} / \mathrm{min}$ for five minutes and inhibited acetylcholine induced dilation of coronary resistance vessels. However, we did not administer high dose L-NMMA because of the risk of increased systemic blood pressure and concomitant vasoconstriction in other vascular beds.

The doses of magnesium infused in the present study were only $0.02 \mathrm{mmol} / \mathrm{min}$ and $0.2 \mathrm{mmol} / \mathrm{min}$. Because changes in systemic haemodynamics with magnesium infusion needed to be avoided and because there were limitations in the amount of time the catheters could be left in the coronary artery, we infused magnesium at only two doses. Furthermore, it has been reported that the intracellular magnesium concentration does not respond rapidly to changes in the extracellular magnesium concentration. ${ }^{37}$ Therefore, it is unlikely that small differences in the extracellular magnesium concentration affected the coronary responses to the first and second intracoronary infusion of magnesium.

CONCLUSIONS

The present findings indicate that intracoronary magnesium infusion causes dilation of human coronary arteries, including conductance and resistance arteries. This magnesium induced human coronary dilation occurs in a dose dependent manner and is independent of EDNO. This magnesium induced coronary dilation may, in part, explain the beneficial effects of magnesium infusion in patients with coronary artery disease.

We are grateful to Tetsuya Oshima MD of the Department of Clinical Laboratory Medicine, Hiroshima University School of Medicine, and to Nobuo Shiode MD, Yukihito Higashi MD, Hidekazu Hirao MD, Shota Sasaki MD, and Yukihiro Fukuda MD of the First Department of Internal Medicine, Hiroshima University School of Medicine, for their technical assistance and helpful comments. We also thank Miss Yuko Omura for her secretarial assistance.

1 Rasmussen HS, Aurup P, Hojberg S, et al. Magnesium and acute myocardial infarction. Transient hypomagnesemia not induced by renal magnesium loss in patients with acute myocardial infarction. Arch Intern Med 1986;146:872-4.

2 Goto K, Yasue H, Okumura K, et al. Magnesium deficiency detected by intravenous loading test in variant angina pectoris. Am f Cardiol 1990;65:709-12.

3 Haigney MC, Berger R, Schulman S, et al. Tissue magnesium levels and the arrhythmic substrate in humans. f Cardiovasc Electrophysiol 1997;8:980-6.

F Cardiovasc Electrophysiol 1997;8:980-6.
4 Woods KL, Fletcher S, Roffe C, et al. Intravenous magnesium sulphate in suspected acute myocardial magnesium sulphate in suspected acute myocardial infarction: results of the second Leicester intravenous mag-
nesium intervention trial (LIMIT-2). Lancet 1992;339: nesium

5 Kugiyama K, Yasue H, Okumura K, et al. Suppression of exercise-induced angina by magnesium sulfate in patient with variant angina. $\mathcal{F} \mathrm{Am}$ Coll Cardiol 1988;12:1177-83.

Tzivoni D, Keren A, Cohen AM, et al. Magnesium therapy for torsades de pointes. Am $\mathcal{F}$ Cardiol 1984;53:528-30.

7 Parikka H, Toivonen L, Pellinen T, et al. The influence of intravenous magnesium sulphate on the occurrence of atrial fibrillation after coronary artery by-pass operation. Eur Heart F 1993;14:251-8.
8 Redwood SR, Bashir Y, Huang J, et al. Effect of magnesium sulphate in patients with unstable angina. A double blind, randomized, placebo-controlled study. Eur Heart f 1997; 18:1269-77.

9 Kimura T, Yasue H, Sakaino N, et al. Effects of magnesium on the tone of isolated human coronary arteries. Comparison with diltiazem and nitroglycerin. Circulation 1989;79: $1118-24$

10 Yusuf S, Teo K, Woods K. Intravenous magnesium in acute myocardial infarction. An effective, safe, simple, and inexpensive intervention. Circulation 1993;87:2043-6.

11 Shechter M, Kaplinsky E, Rabinowitz B. The rationale of magnesium supplementation in acute myocardial infarction. A review of the literature. Arch Intern Med 1992;152: 2189-96.

12 Vigorito C, Giordano A, Ferraro P, et al. Hemodynamic effects of magnesium sulfate on the normal human heart. Am 7 Cardiol 1991;67:1435-7.

13 Vigorito C, Giordano A, Ferraro P, et al. Reduction of pacing-induced myocardial ischemia by intravenous magnesium sulfate. Am f Cardiol 1995;75:280-2.

14 Altura BT, Altura BM. Endothelium-dependent relaxation in coronary arteries requires magnesium ions. $\mathrm{Br} f$ Pharmacol 1987;91:449-5

15 Kemp PA, Gardiner SM, Bennett T, et al. Magnesium sulphate reverses the carotid vasoconstriction caused by endothelin-I, angiotensin II and neuropeptide-Y, but not that caused by $\mathrm{N}^{\mathrm{G}}$-nitro-L-arginine methyl ester, in conscious rats. Clin Sci 1993;85:175-81.

16 Pearson PJ, Evora PR, Seccombe JF, et al. Hypomagnesemia inhibits nitric oxide release from coronary endothelium: protective role of magnesium infusion after cardiac operations. Ann Thorac Surg 1998;65:967-72.

17 Fonseca FA, Paiva TB, Silva EG, et al. Dietary magnesium improves endothelial dependent relaxation of balloon injured arteries in rats. Atherosclerosis 1998;139:237-42.

18 Kato M, Shiode N, Yamagata T, et al. Bradykinin induced dilatation of human epicardial and resistance coronary arteries in vivo: effect of inhibition of nitric oxide synthesis. Heart 1997;78:493-8.

19 Fujita T, Ito Y, Ando K, et al. Attenuated vasodilator responses to $\mathrm{Mg}^{2+}$ in young patients with borderline hypertension. Circulation 1990;82:384-93.

20 Shiode N, Morishima N, Nakayama K, et al. Flow-mediated vasodilation of human epicardial coronary arteries: effect of inhibition of nitric oxide synthesis. F Am Coll Cardiol 1996; 27:304-10.

21 Cox DA, Vita JA, Treasure CB, et al. Atherosclerosis impairs flow-mediated dilation of coronary arteries in humans. Circulation 1989;80:458-65.

22 Iseri LT, French JH. Magnesium: nature's physiologic calcium blocker. Am Heart F 1984;108:188-93.

23 Turlapaty PD, Altura BM. Extracellular magnesium ions control calcium exchange and content of vascular smooth control calcium exchange and content of

24 Altura BM, Altura BT. Magnesium ions and contraction of vascular smooth muscles: relationship to some vascular disease. Fed Proc 1981;40:2672-9.

25 Yoshimura $M$, Oshima T, Matsuura $\mathrm{H}$, et al. Extracellular $\mathrm{Mg}^{2+}$ inhibits capacitative $\mathrm{Ca}^{2+}$ entry in vascular smooth muscle cells. Circulation 1997;95:2567-72.

26 Mallet RT, Sun J, Fan WL, et al. Magnesium activated adenosine formation in intact perfused heart: predominance of ecto 5'-nucleotidase during hypermagnesemia. Biochim Biophys Acta 1996;1290:165-76.

27 Levy JV. Effect of choline magnesium trisalicylate on prostacyclin production by isolated vascular tissue of the rat. Thromb Res 1983;29:149-54.

28 Nadler JL, Goodson S, Rude RK. Evidence that prostacyclin mediates the vascular action of magnesium in humans. Hypertension 1987;9:379-83.

29 Laurant $\mathrm{P}$, Moussard C, Alber D, et al. In vivo and in vitro magnesium effects on aortic prostacyclin generation in DOCA-salt hypertensive rats.
Fatty Acids 1992;47:183-6.

30 O'Brien WF, Williams MC, Benoit R, et al. The effect of magnesium sulfate infusion on systemic and renal prostacyclin production. Prostaglandins 1990;40:529-38.

31 Ravn HB, Vissinger H, Kristensen SD, et al. Magnesium nhibits platelet activity: an infusion study in healthy volunteers. Thromb Haemost 1996;75:939-44.

32 Ravn HB. Pharmacological effects of magnesium on arterial thrombosis: mechanisms of action? Magnes Res 1999;12: $191-9$.

33 Ann HS, Ku DD. Magnesium inhibits basal release of endothelium-derived relaxing factor in canine coronary arteries. Eur 7 Pharmacol 1986;130:353-5.

$34 \mathrm{Ku} \mathrm{DD}$, Ann HS. Differential effects of magnesium on basal and agonist-induced EDRF relaxation in canine coronary and agonist-induced EDRF relaxation in canine cor

35 Cartier R, Hollmann C, Buluran J, et al. Effects of modified St Thomas' Hospital solution on coronary artery endothelium dependent relaxation in the isolated rat heart. Can $\mathcal{F}$ Cardiol 1995;11:53-8.

36 Quyyumi AA, Dakak N, Andrews NP, et al. Nitric oxide activity in the human coronary circulation. Impact of risk factors for coronary atherosclerosis. F Clin Invest 1995;95: 1747-55.

37 Yoshimura M, Oshima T, Matsuura $\mathrm{H}$, et al. Assessment of platelet cytosolic concentration of free magnesium in healthy subjects. F Lab Clin Med 1995;125:743-7. 